Article

\title{
Why Are the Largest Social Networking Services Sometimes Unable to Sustain Themselves?
}

\author{
Yong Joon Hyoung $1, *\left(\mathbb{D}\right.$, Arum Park ${ }^{2}$ and Kyoung Jun Lee ${ }^{1,2}$ \\ 1 Department of Social Network Science, Kyung Hee University, Seoul 02447, Korea; klee@khu.ac.kr \\ 2 School of Management, Kyung Hee University, Seoul 02447, Korea; penellope007@gmail.com \\ * Correspondence: yong.hyoung@gmail.com
}

Received: 11 November 2019; Accepted: 13 December 2019; Published: 9 January 2020

\begin{abstract}
The sustainability of SNSs (social networking services) is a major issue for both business strategists and those who are simply academically curious. The "network effect" is one of the most important theories used to explain the competitive advantage and sustainability of the largest SNSs in the face of the emergence of multiple competitive followers. However, as numerous cases can be observed when a follower manages to overcome the previously largest SNS, we propose the following research question: Why are the largest social networking services sometimes unable to sustain themselves? This question can also be paraphrased as follows: When (under what conditions) do the largest SNSs collapse? Although the network effect generally enables larger networks to survive and thrive, exceptional cases have been observed, such as NateOn Messenger catching up with MSN Messenger in Korea (Case 1), KakaoTalk catching up with NateOn in Korea (Case 2), Facebook catching up with Myspace in the USA (Case 3), and Facebook catching up with Cyworld in Korea (Case 4). To explain these cases, hypothesis-building and practice-oriented methods were chosen. While developing our hypothesis, we coined the concept of a "larger population social network" (LPSN) and proposed an "LPSN effect hypothesis" as follows: The largest SNS in one area can collapse when a new SNS grows in another larger population's social network. For the validity and reliability of our case studies, we used an evidence chain and case study protocol with a publicly-accessible LPSN index to determine which SNS is better for participating in or adding offline social networks to their platform.
\end{abstract}

Keywords: network effect; larger population social network; social network; business sustainability; network sustainability

\section{Introduction}

Some of the most powerful companies in the world are social networking services (SNSs) such as Facebook or mobile instant messaging services like WhatsApp, Line, WeChat, and KakaoTalk. They dominate countries or a wide range of continents. In Korea, KakaoTalk is so strong that even the most dominant portal, Naver, never tries to compete with it, while Facebook or LinkedIn are so strong on a global scale that nobody tries to defeat them. However, what if we can provide meaningful information with which one can decide whether it is worth trying?

We chose practice (rather than theory)-oriented research for our methodology because the motivation for this study comes from working in the social networking service industry. Among the three options for practice-oriented research, we chose the hypothesis-building (instead of the descriptive or hypothesis-testing) method because we want to determine why and how the largest SNS can collapse even with their network effects advantage. There are three traditional case study methods: exploratory, descriptive, and explanatory. We chose explanatory for the purposes of this research, which includes a case study (or case studies) aimed at explaining how or why certain phenomena came to be. Explanation 
models and multiple case study methods are strongly recommended by Yin, which was a factor in our decision to utilize them [1].

These research results can provide valuable clues as to whether Facebook, LinkedIn, Line, or KakaoTalk can be destroyed by a competitor in the future. Facebook, an SNS that was developed relatively recently, defeated Myspace in the USA and Cyworld in Korea, which were the first SNSs in those countries. Under what circumstances can a dominant SNS be destroyed by a newer entrant and competitor? To answer this question, we developed an LPSN effect hypothesis as follows: If a leading SNS does not have the majority of the offline social network universe using its platform, then it can be defeated by a newer competitor who can obtain a larger social network population more quickly. In other words, if the LPSN index (width rate $\times$ depth rate) of the first SNS becomes smaller than the newer SNS's index, the newer SNS can easily overtake the older one, where the width rate = the number of users/local population, and the depth rate $=$ the average number of first-degree friends in the SNS/the Dunbar Number [2]. This hypothesis means that a company that eventually gains a larger social network population or effectively replicates an offline real social network will enjoy the benefits of the network effect.

To verify this hypothesis in line with the explanation research method, we chose multiple case studies. In addition, in line with our case study protocol, we chose four cases in which the newer SNS overtook the older, dominant SNS, as follows:

The first case study involves MSN messenger, which was once Korea's largest PC instant messenger service, being overtaken by NateOn in Korea [3]. The second one focuses on NateOn, after achieving dominance, being overtaken by KakaoTalk, which was initially a mobile messenger service [4]. The third focuses on when Myspace was overtaken by Facebook [5]. The fourth investigates Facebook overtaking Cyworld, which was once the largest social network in Korea [6].

\section{Literature Review}

The network effect has traditionally been used to explain the competitive advantage possessed by market-leading companies, including SNSs. As a company's size crosses the network effect threshold, its network effect increases exponentially. As a result, the company can completely overtake its competitors [7,8] and increase the switching cost of consumers [9]. The company can then enjoy monopolistic profits [10]. If a company with market dominance enjoys the benefits of the network effect, then late market entrants or established competitors will find it difficult to beat that company [11].

However, sometimes online SNSs that already dominate the market have been defeated by later entrants and competitors. Therefore, it is natural to ask why this happens in spite of the network effect [3-6,12]. There is a dearth of research on this question, especially in the online SNS industry. As a methodology for this study, we adopt a multiple-case study methodology, including four cases. In each case, the first SNS is repulsed by the later one. There is a copious amount of literature on existing network effects, but there is no specific and direct research on how a late SNS can defeat the existing, largest one.

The network effect means that a network's value increases as its size increases. There are several other definitions for network effect in economics literature. Katz and Shapiro describe the source of positive consumption externalities as the "utility that a user derives from consumption of goods" which "increases with the number of other agents consuming the (same) good" [13]. Katz and Shapiro newly define network effects as "the value of (a) membership to one user (which) is positively affected when another user joins and enlarges the network" [14]. Church et al. emphasize that "network effect exists if consumption benefits depend positively on the total number of consumers who purchase compatible products" [15]. Literally, all kinds of consumption with positive feedback on the supply and consumer sides could be subsumed under the terms of the network effect and network externalities.

Here we can briefly summarize the famous three Laws of Network Effect:

- Sarnoff's Law: David Sarnoff led the Radio Corporation of America (which created NBC) from 1919 until 1970. It was one of the largest networks in the world during those years. Sarnoff observed 
that the value of his network seemed to increase in direct proportion to its size-proportional to $\mathrm{N}$, where $\mathrm{N}$ is the total number of users on the network. Sarnoff's description of network value ended up being an underestimate for SNS types of networks, although it was an accurate description of broadcast networks with a few central nodes broadcasting to many marginal nodes (a radio or television audience).

- Metcalfe's Law: Metcalfe's Law states that the value of a communications network grows in proportion to the square of the number of users on the network $\left(\mathrm{N}^{2}\right.$, where $\mathrm{N}$ is the total number of users on the network). The formulation of this concept is attributed to Robert Metcalfe, one of the inventors of the Ethernet standard. Metcalfe's Law seems to hold because the number of links between nodes on a network increase mathematically at a rate of $\mathrm{N}^{2}$, where $\mathrm{N}$ is the number of nodes. Although originally formulated to describe communication networks like the ethernet, faxing or phones, with the arrival of the internet, it has evolved to describe SNSs as well.

- Reed's Law: Reed's Law was published by David P. Reed of MIT in 1999. While Reed acknowledged that "many kinds of value grow proportionally to network size" and that some grow as a proportion to the square of network size, he suggested that "group-forming networks" that allow for the formation of clusters (as described above) scale value even faster than other networks. Group-forming networks, according to Reed, increase value at a rate of $2^{\mathrm{N}}$, where $\mathrm{N}$ is the total number of nodes on the network. Reed suggested a formula of $2^{\mathrm{N}}$ instead of $\mathrm{N}^{2}$ because the number of possible groups within a network that "supports easy group communication" is much higher than 1 so that the total number of connections in the network (the network density) is not just a function of the total number of nodes $(\mathrm{N})$. In reality, it is a function of the total number of nodes plus the total number of possible sub-groupings or clusters, which scales at a much faster rate with the addition of more users to the network. Since most online networks allow for the formation of clusters, they will likely behave at least somewhat as Reed's Law suggests and grow in value at a much faster rate than either Metcalfe's Law or Sarnoff's Law suggests.

The range of networks effect that we mainly want to deal with in this paper is produced by SNS, such as Myspace, Cyworld, Facebook, Whatsapp, Line, KakaoTalk, and WeChat. The effect is related to Metcalfe's Law or Reed's Law. All of these services assume initial consent for connecting new people online by using the real names used in daily life. This paper concentrates only on the SNSs that have accumulated offline social network- and offline relationships-related data.

This study focuses on cases in which network effect did not seem to be working, as each case only included the largest SNS defeated by a newer one. All of the literature dealing with network effects is based on the assumption that network effects have already been achieved and companies use various tactics to firmly maintain it by maximizing the switching cost of the carrier or employing a complementary strategy [16], such as integrating portal services [17], collaborating with partners on an API [18,19], utilizing a CEO's ability [20], adapting to environmental change, or providing user satisfaction [21], none of which are pertinent to why network effects fail or continue to succeed. These articles point out that network effects are extremely important, hard to break, and require a variety of tactics to continue. But nowadays, there are more and more reports questioning network effects and providing examples of the downfall of services that once had the largest networks [22-25].

There is a misbelief that the emergence of a new technology paradigm means that the existing network effects are almost inoperable. As the PC era transforms into the mobile era, with disruptive innovations, those who once enjoyed such network effects have changed. There is also a new argument that network effects alone are not enough. In the case of online marketplaces, it is difficult to grow too quickly; or, if an SNS fails to build trust, network effects cannot be sustained [26,27]. Also, as an existing network becomes saturated, it collapses due to leakage of personal information and stalking from an overflow of content and excess of people [28].

However, even in the above studies, we could not figure out why the first SNS, which enjoyed the network effect, could fall even if they followed recommendations or overcame problems by providing new service features. We later realized that this was because they only considered either external factors, 
such as rapid environmental change or technological change, which are relatively difficult to control, or superficial factors like user interface. Additionally, little research has been undertaken to investigate why this exceptional phenomenon (i.e., latecomers overtaking the older ones) transpires, and currently, available research only superficially touches upon the nature of the social network [29,30].

On the other hand, this study focuses on the verification of the hypothesis that, if any online SNS cannot occupy most of the offline social network's "large set", it can fail at any time if another SNS continues to occupy the "large set" faster than the first. This is different from Tucker's central argument [25], which claims that network effects do not work well in comprehensive cases, including the marketplace, riding apps like Uber, SNSs, and music services. Rather, our study shows that network effects still work well, especially within the SNS industry, and that only those who properly understand the nature of the social network itself can sustain its network effect.

\section{Research Method}

Our study is based on a practice-oriented case study methodology. A practitioner requires knowledge to define and solve problems in an identified practice, and this methodology is intended to provide the practitioner with useful knowledge. Dul and Hak divided the types of case study methods into descriptive research, hypothesis-building research, and hypothesis-testing research [31]. Practice-oriented research is a case study to provide knowledge to industrial practitioners. We built hypothesis by conducting case study. Figure 1 shows our hypothesis building research framework.

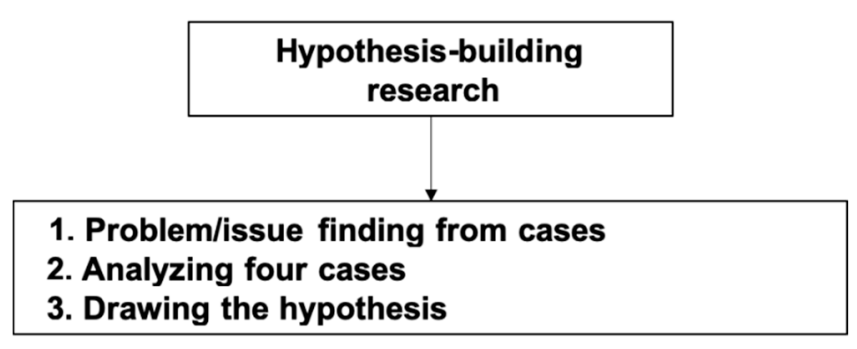

Figure 1. Hypothesis building research.

We defined the problem or topic we want to study and search for relevant theories. Then, we built the hypothesis from four cases. We found same problem and issue from context of four cases that prior theory could not explain. By analyzing each cases, we drew the hypothesis that could the context of four cases.

A case study can describe actual society and provide the opportunity to establish theories based on experience [32]. To enhance this case study's validity and credibility, a research framework was designed, as shown in Table 1, and suggested by Yin [1]. In each case, the pattern-matching method and theory triangulation were performed to verify the hypotheses. Additionally, to reinforce construct validity and provide a clear evidence chain, our researchers collected and compared different data and presented their sources. Furthermore, we tried to generalize Bandara's hypotheses by conducting multiple case studies to secure external validity [33].

1. The purpose of the case study in this paper is to determine which factors enabled latecomers to outperform earlier entrants despite the fact that the latter group was producing the network effect. We investigated cases where this phenomenon was observed with later participants. We have limited the research scope to SNS, one of the industries where the network effect occurs.

2. We performed literature studies on factors that cause the network effect as well as those which enable later participants to overtake first entrants because of the network effect.

3. Case Selection: The four cases analyzed for this study were chosen because they were examples of later participants outperforming first entrants. 
4. Case analysis tool: The unit of a case analysis is the number of users or unique visitors, the market share of each social network service, and the network effect strategy of each company.

5. For the validity of case analysis and hypothesis-building, three researchers collected literary data on each case, compared this to determine the facts, and analyzed all information based on the verified data. In the analysis process, one researcher presented the analysis process and results of one case, and the other two researchers followed the same process and verified the triangulation method to determine whether the same result was reached.

6. Implications: This study proves the hypothesis about which factors enable latecomers to outwit the first entrants. This knowledge can be used as a strategy for a later entrant to increase its market share when the earlier entrant's network effect has occurred.

Table 1. Case study framework.

\begin{tabular}{ll}
\hline \multicolumn{1}{c}{ Case Study } \\
Sequence & \multicolumn{1}{c}{ Research } \\
\hline 1. Case study purpose & Presenting the research purpose for the case study \\
2. Draw a hypothesis & Drawing a hypothesis through literature research and data collection \\
3. Select cases & Selecting cases that meet the set study objectives \\
4. Case analysis tools & Presenting tools and protocols for case analysis \\
5. Case analysis and hypothesis building & Analyzing the selected cases \\
6. Present implications & Drawing implications for case studies from an integrative perspective \\
\hline
\end{tabular}

Among the methods presented by Bent [32], extreme and deviant case selection methods were applied. This method is a useful method for acquiring information about specific cases.

\section{Analysis of the Four Cases}

\subsection{MSN vs. NateOn}

From 2000 to 2004, MSN Messenger was the No. 1 online messenger in Korea and had hundreds of millions of installers around the world. Most PC users installed MSN Messenger and used it for business purposes as well as among friends. However, MSN's market dominance was overturned by latecomer NateOn as early as 2005.

As seen in Figure 2, before 2003, MSN had a bigger LPSN than NateOn in the same PC space in Korea. The number of PC-based MSN social network users in Korea was about 6 million, which was much larger than that of PC-based NateOn social network users in Korea.

Since 2005, NateOn integrated both the social network of Cyworld, i.e., NateOn_SN (Cyworld; represented in Figure 3) and the cellular phone address book social network, i.e., NateOn_SN (Cellular), into its PC-based social network, i.e., existing NateOn messenger, NateOn_SN (PC).

With the integration, NateOn constructed a bigger LPSN than MSN in the PC space in Korea, as depicted in Figure 3.

In addition, NateOn replicated offline social networks more deeply. Although MSN's global social network was bigger than NateOn's, MSN could not occupy the majority of the offline local social networks in Korea. Therefore, it could not keep its No. 1 position in Korea.

In August 2005, NateOn provided 100 free SMS messages every month and the button for "onestep login" to Cyworld. The free SMS function was a great help in securing the installation base, and the login linkage with Cyworld and the Cyworld notification functionality provided the main driving force for continuous use of the NateOn messenger. By installing the NateOn Messenger, users could download their cell phone address books into the PC messenger and then easily send text messages to any friend in their address book with just one click in Messenger, which provided a strong incentive to install the NateOn Messenger. SK Telecom (SKT), the NateOn Messenger operator, was the number one cellular carrier company with a market share of over $50 \%$ at that time. The marketing power of the monthly 100 free text messages for its 20 million cellular network subscribers was a 
powerful weapon for outpacing the number of MSN Messenger users (about 6 million at the time). Cyworld, at that time, had 15 million users and was still growing.

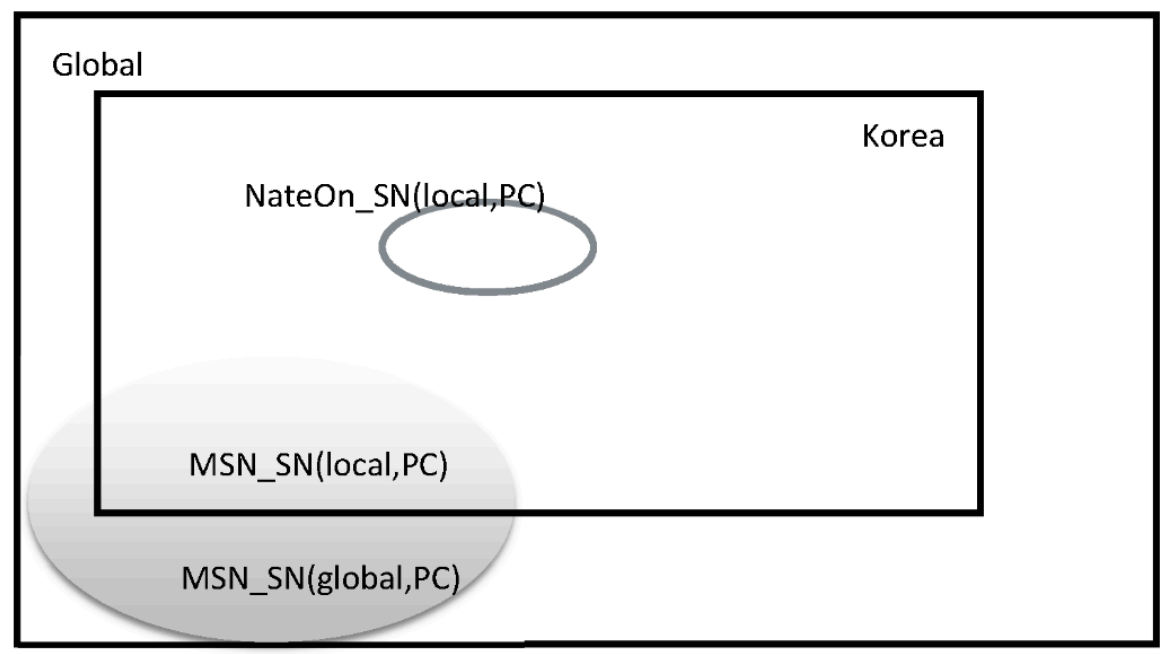

Figure 2. MSN IM and NateOn IM offline Social Network Occupation map in 2003.

- [Before 2003: MSN had bigger LPSN than NateOn.]

- $\quad$ MSN_SN (local, PC) > NateOn_SN (local, PC) or $(\mathrm{MSN}=10 \mathrm{M}$ users $>$ NateOn $=0)$

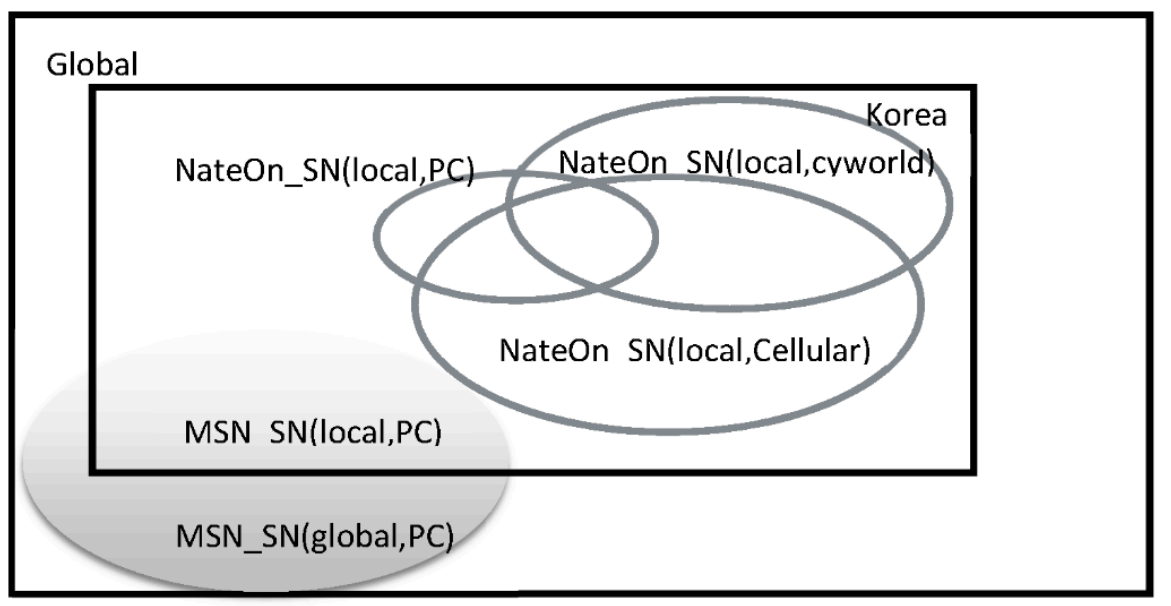

Figure 3. MSN IM and NateOn IM offline Social Network Occupation map in 2005.

- [After 2005: NateOn made bigger LPSN than MSN at Korea PC space.]

- $\quad$ MSN_SN (local, PC) < [NateOn_SN (local, PC) $\cup$ NateOn_SN (local, Cyworld) U NateOn_SN (local, Cellular)]

- $\quad$ Or $(\mathrm{MSN}=6 \mathrm{M}$ users $<$ NateOn users 10M $\cup$ Cyworld users $15 \mathrm{M} \cup$ cell phone users $20 \mathrm{M})$

As a result, whereas MSN only occupied the Korea PC-space social network, which was much smaller than the offline, real social network (40 million Korean population in total), NateOn, by utilizing the cell phone address book (which included over 20 million people, more than $50 \%$ of the entire population) and Cyworld's first-degree friend lists (the only one, and the largest SNS in Korea at that time, with 15 million users and growing), was able to overtake MSN Messenger's No. 1 position in the Korean PC messenger market. 


\subsection{NateOn vs. KakaoTalk}

In 2006, NateOn completely outperformed MSN Messenger, the previous No. 1 market player, in terms of the number of installers and monthly visitors. Before 2010, NateOn, represented as NateOn_SN (Korean, PC) in Figure 4, had a bigger LPSN in the PC space than KakaoTalk's, represented as KakaoTalk_SN (local, mobile), which was growing in the mobile space. The number of NateOn_SN (Korean, PC) users was 12 million and the mobile IM, KakaoTalk, had just started.

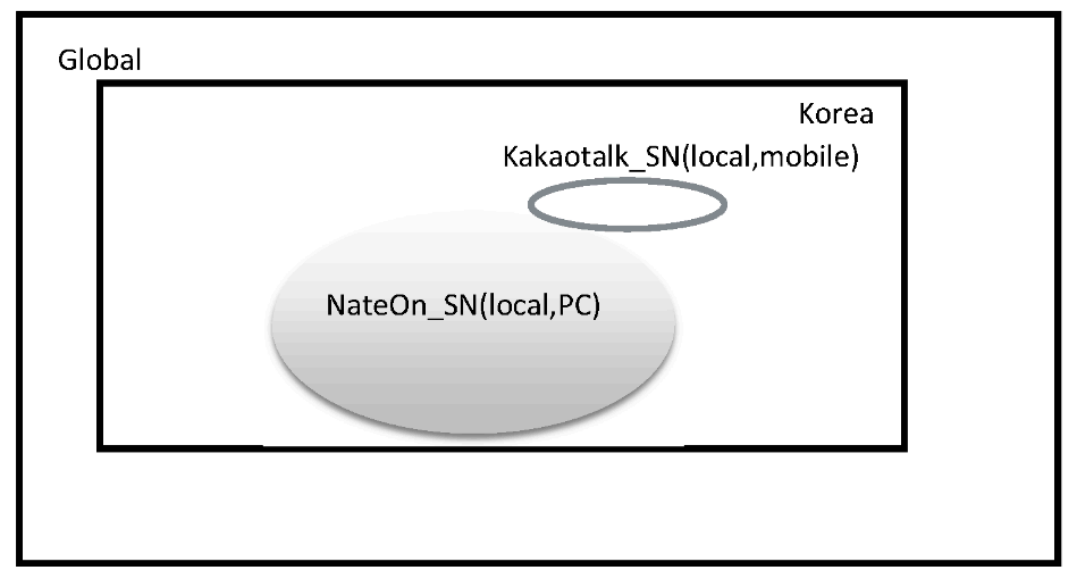

Figure 4. NateOn and KakaoTalk offline Social Network Occupation map in 2010.

- [Before 2010: NateOn had bigger LPSN than KakaoTalk at Korea PC space.]

- NateOn_SN (local, PC) > [KakaoTalk_SN (local, PC) U KakaoTalk_SN (local, mobile)]

- $\quad($ NateOn $=12 \mathrm{M}$ (but locally saturated in PC) $>[(0=$ KakaoTalk PC IM $)+$ mobile IM growing $]$

Since 2010, KakaoTalk has steadily defeated several competing mobile messengers in Korea, gaining more than 42 million mobile users in 2012, which accounts for a majority of the Korean population (reflecting most of the offline social network).

KakaoTalk occupied the mobile messenger market in a short period. On the other hand, the once No. 1 PC messenger NateOn, which beat out MSN messenger, has been saturated in the smaller-population social network that is Korea PC space.

KakaoTalk is a mobile messenger app that allows users to send free text/photo messages to any of their friends. Because of this strong benefit, users were willing to send "invitations" to their friends, who accepted them. Thus, it spread quickly in such a viral manner. Similar to the 100 free texts per month of NateOn, the free text messaging feature between friends has played a major role in quickly creating an enormous installation base. On the other hand, NateOn PC Messenger also launched its mobile messenger quite late. Since its parent company SKT, Korea's largest telecommunications company, made close to 1 billion USD per year in short text messaging sales at that time, it hesitated to strengthen its mobile presence. In June 2013, KakaoTalk, which already had 40 million mobile users, started a new PC version of KakaoTalk IM and overwhelmed NateOn messenger within just nine months.

A smartphone is always connected online and in real-time, unlike a PC. In addition, because it is a phone, it is utilized as an essential product, whereas a PC is utilized heavily by only some workers and temporarily by students and most people. In other words, a PC is a tool that exists apart from people, whereas a smartphone is equivalent to the entity of a person. Mobile messenger users use the PC version of the same messenger service for reasons such as the convenience of continuous use of a mobile messenger's contacts, typing long texts using a big keyboard, and sending files. 
In previous sections, we hypothesized that an SNS which occupies most of the offline social network universe would be the final winner in exercising the everlasting network effect. The medium that better captures offline social networks can change as technology advances. As technology innovation migrates from PCs to cellphones and then smartphones, innovative media which better captures offline social networks is essential in order to maximize or sustain network effects. However, merely migration to the mobile world or new tech platform will not be sufficient. Keeping the focus on accumulating offline social networks should be a higher priority.

As seen in Figure 5, after 2013, KakaoTalk achieved a bigger LPSN than NateOn, even in the PC space, let alone the mobile space.

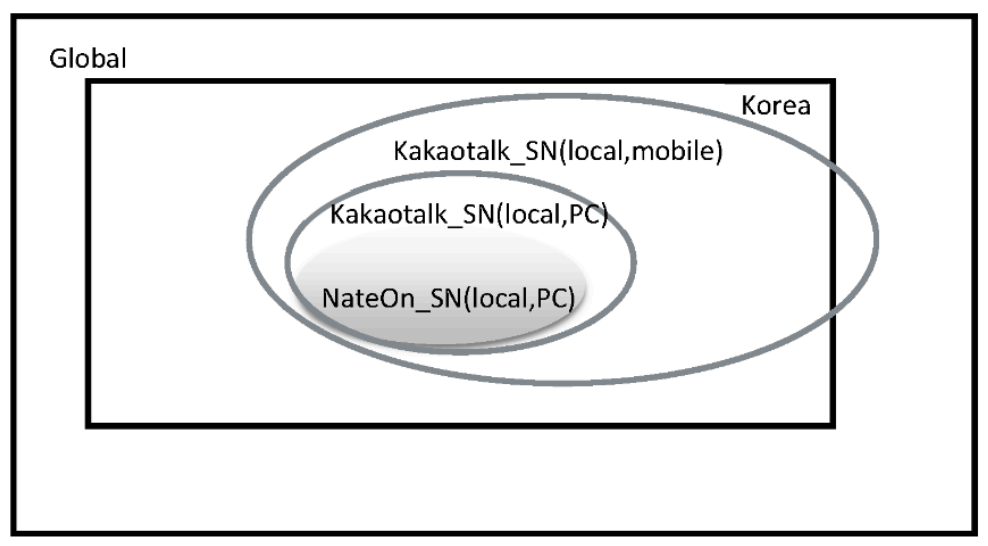

Figure 5. NateOn and KakaoTalk offline social network occupation map in 2013.

- [After 2013: KakaoTalk had bigger LPSN than NateOn at Korea PC space.]

- $\quad$ [NateOn_SN (local, PC)] < [KakaoTalk_SN (local, mobile) includes KakaoTalk_SN (local, PC)]

- $\quad($ NateOn $=6 \mathrm{M}$ (but decreasing) $<[40 \mathrm{M}$ mobile users includes PC IM users 5M (but rapidly growing) $]$

\subsection{Myspace vs. Facebook}

In 2007, Myspace was the largest SNS in the United States, as can be seen in Figure 6. However, in 2013, its position was overtaken by latecomer Facebook. Unlike Korea, the United States still had a bigger LPSN in the PC space in 2013. Myspace did not occupy more than $30 \%$ of the offline social network space and failed to continue building up its offline social network databases. In the end, even within the PC space, Myspace was defeated by Facebook. Additionally, as the mobile space provides larger containers for fetching offline social networks, Facebook steadily collected more of the offline social networks using its mobile app.

In 2013 in the United States, most users accessed their online SNSs through a PC rather than a mobile phone because the mobile penetration rate was not yet that high in the US. Facebook had already surpassed Myspace in the US in terms of monthly active users, largely by occupying offline social networks consisting of university and high-school students. Facebook also had a strong presence in foreign countries through university and college students abroad.

In Figure 7, Facebook_SN (Global, PC + mobile) means Facebook used the global network and used PC + mobile, Myspace_SN (local, PC) means that Myspace focused on domestic (i.e., the USA) social networks rather than global ones and it also focused on PC networks rather than mobile ones. 


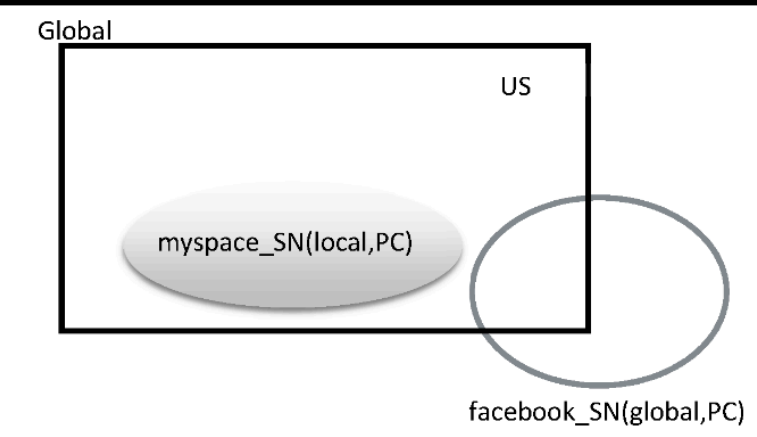

Figure 6. Myspace and Facebook offline social network occupation map in 2007.

- [Before 2007: Myspace had bigger LPSN than FB at USA PC space]

- \# of Users of Myspace_SN (USA, PC) > \# of Users of Facebook_SN (USA, PC)]

- Where \# of Users of Myspace_SN (USA, PC) = 110M and \# of Users of Facebook_SN (USA, PC)] = 30M

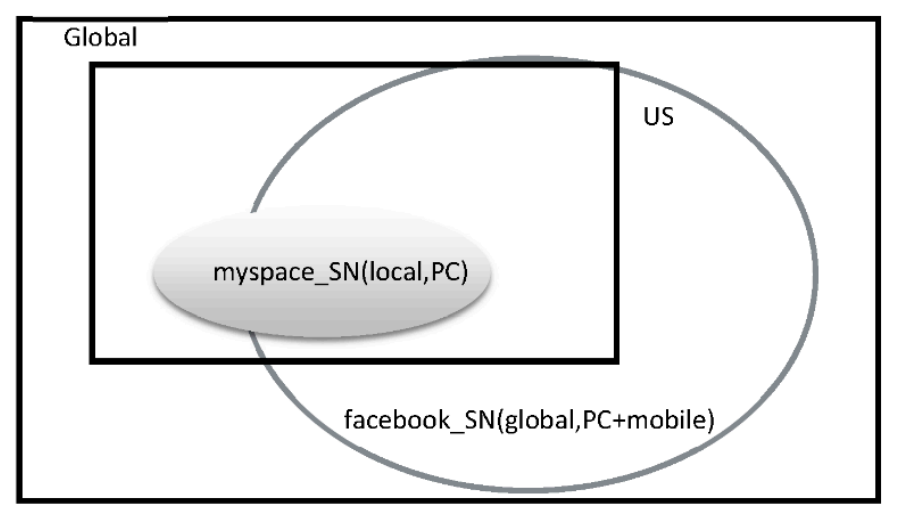

Figure 7. Myspace and Facebook offline social network occupation map in 2013.

- [After 2013: FB made bigger LPSN than Myspace at USA PC space.]

- Myspace_SN (USA, PC) < [Facebook_SN (Global, PC) U Facebook_SN (Global, mobile)]

- Where \# of Users of Myspace_SN (USA, PC) = 20M and \# of Users of Facebook_SN (Global, $\mathrm{PC})=1.3 \mathrm{~B}$ and \# of Users of Facebook_SN (Global, mobile $)=0.9 \mathrm{~B}$

Before 2013, Myspace was the representative SNS in the United States. Myspace was acquired by Rupert Murdoch's News Corporation at about 700 million USD. At this time, Mark Zuckerberg of Facebook said that it was a matter of time before Myspace was taken over by Facebook because the new owners did not know the nature of the social network. Mike Jones, former president of Myspace, said in an interview, "I believe that Facebook was able to keep up with Myspace because it made the social network perfect, whereas Myspace just introduced the social network to people [29]." Myspace encouraged anonymous systems, which increasingly hindered the enjoyment of social networks. On the other hand, Facebook continued to encourage people to use their real names. This important difference in the two SNSs will serve as a game-changer in the future. The use of real names is the basic requirement for bringing offline social networks online.

In 2003, when Myspace flourished, only 7\% of the US population used an SNS. The market Myspace preempted was a small share of the US population. So, it was providing sufficient opportunity for the potential latecomer. Furthermore, Myspace was not interested in hardening its precious networks created based on its actual offline social network, as shown in the above interviews, and continued to make mistakes that broke or diluted the pure social network connections already built. As a result, 
the SNS was used for illegal activities such as prostitution. This is an inevitable consequence of emphasizing anonymous activities.

It should be noted here that transforming an offline social network into an online one requires strategy. The largest offline social network is society itself, and the best place to clone a society, if you can weave a contact list to another contact list that follows an overlapped person, is the address book on cell phone networks or mobile phones. Thus, with a mobile messenger service, it is relatively easy to build a first-degree (friends) network by absorbing the mobile phone address book. However, it was not easy to replicate the offline social network in the online or PC world, where the anonymous culture is strong and true user identity is difficult to verify. Accordingly, Facebook founder Mark Zuckerberg initially sent e-mail invitations to Harvard students whom he already knew. Because of this, Facebook first consisted of mostly Harvard students and then expanded its invitations to other Ivy League students. Later, it expanded again to the remaining college or university students in the world. In other words, the SNS has grown by successfully transforming offline social networks into an online social network. After taking control of most US college offline social networks and expanding the invitation to international students, Facebook naturally entered the global market. The culture and habit of using a real name might have initially been awkward for the online PC world's anonymous name culture, but after users were invited, they became used to the requirement. After this, Facebook opened to the general public without requiring an invitation-only, so that follow-up subscribers naturally behaved according to the existing culture and inertia.

\subsection{Cyworld vs. Facebook}

Cyworld was officially launched in August 1999 after changing its name from PeopleSquare, which was founded in 1998. SKT took over Cyworld in 2003 and invested in server infrastructure. Cyworld grew rapidly, absorbing more than $51 \%$ of the Korea population, more than 25 million users. It has grown to generate revenue of 100 million USD annually, mostly with digital item selling.

By 2009, Cyworld was Korea's largest SNS, as can be seen in Figure 8. In 2013, the LPSN shifted from PC to mobile, but before that, even in the PC space, Cyworld had been overwhelmed by Facebook (Figure 9). Cyworld was attacked from two directions as follows:

First, Facebook, which had built up a steady network of offline social networks, connected Koreans to the global network. Cyworld, on the other hand, simultaneously established branch offices in China, Germany, the USA, and Japan, and built a separate social network database for each country without connecting them.

Ignoring the basic global expandability of offline social networks, Cyworld Korea was isolated from the Cyworld China membership database, US users, and all other country users. As a result, Korean Cyworld users living in Korea had to sign up to use American Cyworld to meet foreign friends living in the US, and if a relative who had lived in Korea went to the United States to study, he/she had to register again with Cyworld USA and had to be invited again. Korean Cyworld users could not invite foreign friends who only spoke English to use their SNS because only Korean menus were provided.

This meant that it lost an enormous opportunity to acquire global social networks utilizing Korea's local network, which was already built into Cyworld at the time. More than $51 \%$ of the population were using Cyworld, including most Korean celebrities. It also meant losing the opportunity to save on significant marketing costs globally.

How Facebook built up the largest social network to include $50 \%$ of the world population should be summarized. As seen in interviews with the former Myspace CEO, Myspace introduced an SNS, but only Facebook mastered it [29]. In short, Facebook insisted on the real-name system and never looked back. This requirement reflects offline society, where we call our friends and family by their real names. On this basis, Facebook executed the open API policy to more quickly acquire offline social networks from each country. 
Second, although Cyworld had an opportunity to occupy a bigger LPSN in the mobile sphere in 2013, the company could not take advantage of it because its parent company, SKT, was reluctant to quickly move to mobile. Cyworld was hesitant to develop a free mobile messaging service because SKT would not give up sales (about 2 billion USD in 2011) in cellular-based short text messaging (SMS). As users became closer with their mobile smartphones than with PCs, they naturally began using alternatives, like Facebook mobile rather than Cyworld online-only, especially because most of their friends were migrating, almost at the same time, to this more flexible choice. Migration occurred because Facebook was fully ready with mobile and global versions to make building an offline social network (by fetching existing online PC users and adding new users through phone address books) easier and faster, resulting in the creation of a global social network based on local social network. Cyworld, by contrast, was stuck in a small, PC market in Korea.

As a result, in 2013, Facebook built a global network by occupying local networks (offline social networks) in each country, acquired bigger LPSN in the growing mobile sector, and completely defeated Cyworld.

In Figure 9, Cyworld_SN (the US, PC) means Cyworld used US social networks separately from Korean or other countries, and it used the PC space only except for mobile.

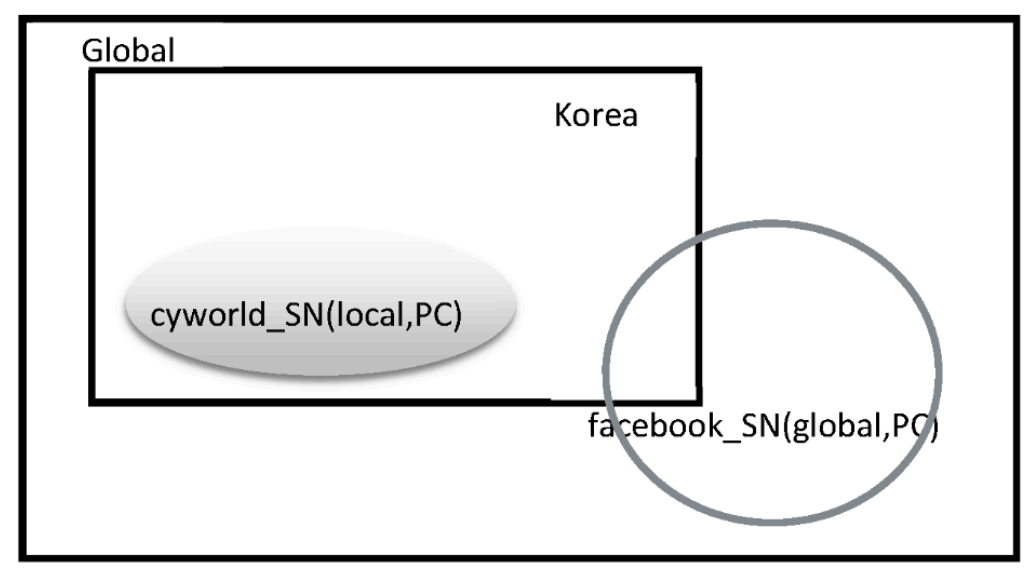

Figure 8. Cyworld and Facebook offline social network occupation map in 2009.

- [Before 2009: Cyworld had bigger LPSN than Facebook at Korea PC space.]

- Cyworld_SN (Korea, PC) > Facebook_SN (Korea, PC) where \# of Users of Cyworld_SN (Korea, $\mathrm{PC})=25 \mathrm{M}$

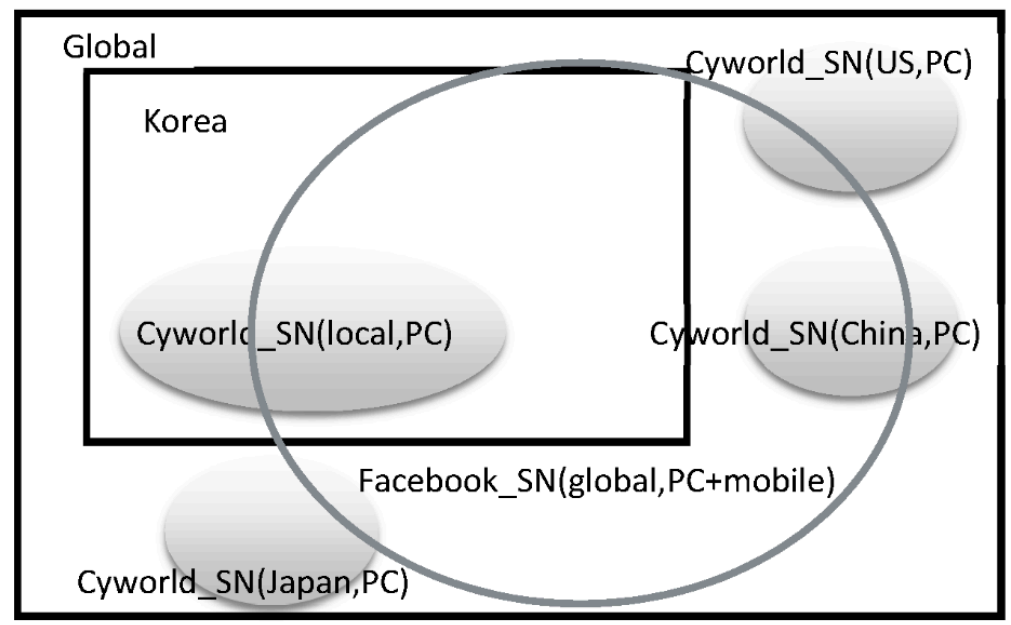

Figure 9. Cyworld and Facebook offline social network occupation map in 2013. 
- [After 2012: Facebook made bigger LPSN than Cyworld at Korea PC space, let alone mobile space.]

- Cyworld_SN (Korea, PC) < Facebook_SN(Korea, PC) $\cup$ Facebook_SN (global, mobile) where \# of Users of Cyworld_SN (Korea, PC) =9M unique visitors/month and \# of Users of Facebook_SN (Korea, mobile $)=13 \mathrm{M}$ unique visitors/month and $\#$ of users of Facebook_SN (global, mobile) $=0.9 \mathrm{~B}$

\section{Construct Definition and Hypothesis Building}

\subsection{Construct Definition}

A network is defined as a set of nodes and links. A social network is a set of nodes and links, where each node represents a person, and a link represents a connection between two persons. Social networking is a behavior of creating, reinforcing, or deleting the relationship between nodes (people). The social relationship between two persons usually, in the real world, starts with some behavior with or without artificial tools, i.e., technologies, such as shaking hands, name card exchange, exchanging eye contact. The relationship can be reinforced, also with or without technology, sometimes called "media", by face-to-face meetings, phone conversations, or texting. Social networking builds a trust-based information-sharing network. SNS refers to a technology-based service that supports social networking. Its examples include PC-based online or phone-based mobile service. In SNS, social networking starts with an email or SMS message to "Invite/Add" friends and "Accept Invitation". In the case of using mobile instant messenger services, automatic retrieval of existing phone address books can be a starting point of the SNS.

All persons build a first-degree relationship with parents or guardians as they are born. They accumulate other first-degree relationships in town and school, and still more as they become involved in social and working lives. These relationships begin to be included in the email lists on PCs, in cell-phone address books, and, nowadays, in mobile messenger apps or SNSs such as Facebook. The concept of social networking has existed from an early age of humankind. However, this study does not deal with chronological social networks. It only considers the period since the Internet and mobile technology and services became popular in 1999 when Cyworld became a corporation and started its business as the first successful social network service in the world.

We differentiate SNS with social media as follows: Social media includes Twitter, Pinterest, and Instagram, companies that mainly treat content but not people, whereas SNS includes Facebook, LinkedIn, Myspace, Cyworld, and instant messenger services that mainly treat friends or contacts first, before contents. In the latter situation, trust-building or social networking itself is important; sharing information is merely a tool for reinforcing the relationship. Usually, the term "social media" includes "SNS", but not vice versa.

Social networks are a social construct that has always existed in offline society long before PCs and smartphones appeared. A social network is a basis for trust-based information sharing and trust-based information distribution, such as job introduction and dating partner introduction. Our daily lives are based on social interaction, for private or business purposes, with those we know. An SNS is a necessary, everyday utility like electricity and water. This is why Mark Zuckerberg termed a "social networking service" as a social utility. This study does not deal with the network effects of all kinds of platforms or all kinds of social media. Instead, it concentrates only on those services that have replicated the offline social network into PC or smartphone-based online platforms. In our study, online/mobile messenger services are regarded as an SNS because they also replicate offline social networks. A messenger service contains lists which cannot be browsed by each friend, and which makes it an optimized tool for one-to-one (or closed-group) communication.

Considering the importance of the network effect of SNSs, we can understand the sustainability of an SNS depends on the occupation and management of the offline social network by the SNS. Every SNS occupies, represents, or replicates a snapshot and a stream of offline social networks using state-of-the-art technologies. An SNS is born based on the technology at a time. The technology on which the SNS is based creates and enlarges the potential population of the social network it aims to 
occupy. We define an LPSN as the social network with a population larger than what existing SNS aims to occupy. The biggest LPSN is the offline social network universe itself. In an individual's view, the LPSN exists in his/her brain than in an offline Rolodex, email, or cell-phone number. The size comparison of the LPSN can be represented by the sign of inequalities as below.

Offline social network > an individual's memory about people he/she once met $>$ Rolodex or digital address book he/she keeps ("container")

The LPSN not only considers the population of one country or world but also relationship information between two selected persons. Even if a mobile space or container (e.g., Rolodex, mobile devices, friends list, or new technologies like VR, AR, or smart glasses) can include a broader or bigger population of one country or world, that is not enough to create an LPSN. Creating an LPSN also requires links or connection information between two persons. As we observed in the aforementioned cases, Facebook outwitted Cyworld and Myspace even before the mobile space era fully arrived, because Facebook kept fetching offline social networks by dragging not only nodes but also links between them, whereas Cyworld and Myspace were negligent in this pursuit. For example, Cyworld used celebrity marketing in China without carefully considering fetching real relationships between users. And NateOn fetched offline social networks by utilizing the existing nodes and links database of an LPSN which had already been created by Cyworld and the SKT cellular network. KakaoTalk fetched offline social networks by utilizing the existing node-and-link database of an LPSN which had already been created on a smartphone phone address book.

We regard the PC-based social network or mobile-based social network as a subset of the offline social network universe. For example, some messenger networks in the PC space have replicated offline social networks, and some mobile messenger networks have done so in the smartphone space. In 2009, when the smartphone era had just started, the PC space had a social network with a population larger than that of the mobile space. However, in 2019, the mobile space had a far larger population social network than that of the PC space. In Korea, the LPSN moved from PC to mobile in 2013. Before 2013, the PC space was a better place to build an SNS. That year, however, the mobile space became the larger space upon which to build social networks that replicated offline social networks (Figure 10).

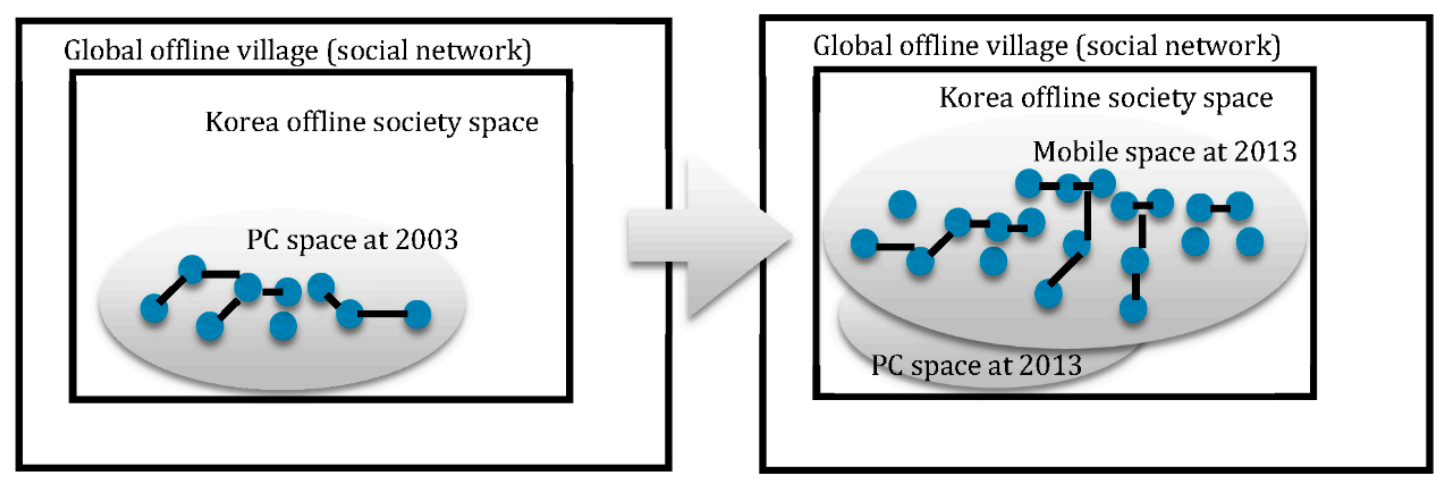

Figure 10. Occupation of larger population social network change in Korea.

\subsection{Hypothesis Building}

Here is our hypothesis: If any SNS cannot occupy a majority of the offline social network universe, it can fail at any time if another SNS continues to occupy the LPSN faster than the first.

Contact information in a cell phone, contact lists on messenger apps, and friends lists in SNS all reflect or replicate a subset of the offline social network universe. An email address on a PC, a phone number on a smartphone, and a messenger ID are recognized as unique reflections of real people. Because some people (whether they be illiterate, too young or poor, blind or simply tech-averse) still do not use a mobile phone or e-mail, the offline social network universe is much larger than merely collections of email addresses or phone numbers. Users in mobile messenger apps or Facebook are all 
subsets of the universal set. Now, smartphone-space has a bigger LPSN than the PC space, in terms of the number of users connected and instantaneous accessibility.

Our hypothesis can be represented in the functional format below.

Hypothesis 1. An SNS that can make the value of "width rate $\times$ depth rate (= LPSN index)" bigger than a competitor, will win the market, where width rate = \# of active users/offline population, depth rate = average \# of connected friends in the SNS/150 (= Dunbar Number)

- width: \# of (active) users in an SNS, cannot be bigger than the offline social network (or population).

- depth: \# of friends of each person (node) in an SNS, the average number of each depth cannot be greater than 150 (Dunbar number).

- Dunbar Number: A theoretical limit to the number of people's names which individuals can memorize for trust-based social relationships (usually considered to be roughly 150) [2].

Let's say our real-world has only eight people, and they are connected to each other like Figure 11. For example, person A has B, C, D and F as friends, and so forth.

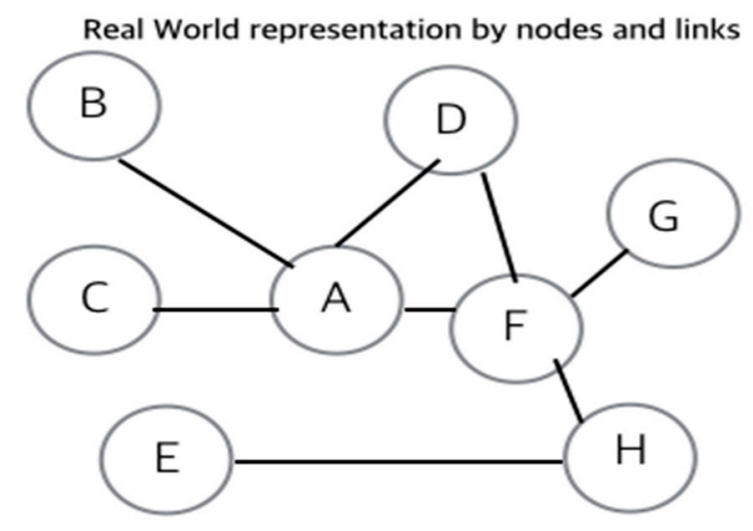

Figure 11. Real World representation.

Now let us say that an SNS is replicated in the real-world like in Figure 12. This means A has not or could not replicate friend B yet and $F$ has not or could not replicate D or G yet, either. (Even if B or $\mathrm{G}$ becomes a member of this SNS, it happens that $\mathrm{A}$ is not yet connected to B or F is not yet connected to G. Let us say they were enemies before.)

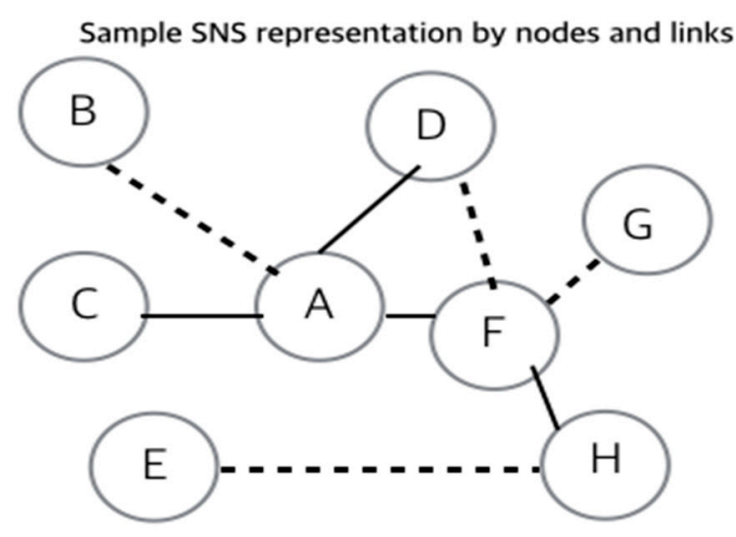

Figure 12. An SNS representation of the real world. 
The above node and links can be represented by matrix form such as Tables 2 and 3 .

- The offline social network universe can be represented by a matrix table like this. A is a person, $\mathrm{B}$ is another person, $\mathrm{C}$ is another person ... living in this society. " 1 " means there is a relationship between two people. " 0 " means there is no relationship between two people.

Table 2. Real-world matrix.

\begin{tabular}{ccccccccc}
\hline & A & B & C & D & E & F & G & H \\
\hline A & 0 & 1 & 1 & 1 & 0 & 1 & 0 & 0 \\
B & 1 & 0 & 0 & 0 & 0 & 0 & 0 & 0 \\
C & 1 & 0 & 0 & 0 & 0 & 0 & 0 & 0 \\
D & 1 & 0 & 0 & 0 & 0 & 1 & 0 & 0 \\
E & 0 & 0 & 0 & 0 & 0 & 1 & 0 & 1 \\
F & 1 & 0 & 0 & 1 & 0 & 0 & 1 & 1 \\
G & 0 & 0 & 0 & 0 & 0 & 1 & 0 & 0 \\
H & 0 & 0 & 0 & 0 & 1 & 1 & 0 & 0 \\
\hline
\end{tabular}

Table 3. Sample SNS matrix.

\begin{tabular}{ccccccccc}
\hline & A & B & C & D & E & F & G & H \\
\hline A & 0 & $\mathbf{0}$ & 1 & 1 & 0 & 1 & 0 & 0 \\
B & 0 & 0 & 0 & 0 & 0 & 0 & 0 & 0 \\
C & 1 & 0 & 0 & 0 & 0 & 0 & 0 & 0 \\
D & 1 & 0 & 0 & 0 & 0 & $\mathbf{0}$ & 0 & 0 \\
E & 0 & 0 & 0 & 0 & 0 & 0 & 0 & $\mathbf{0}$ \\
F & 1 & 0 & 0 & 0 & 0 & 0 & $\mathbf{0}$ & 1 \\
G & 0 & 0 & 0 & 0 & 0 & $\mathbf{0}$ & 0 & 0 \\
H & 0 & 0 & 0 & 0 & $\mathbf{0}$ & 1 & 0 & 0 \\
\hline
\end{tabular}

In this SNS, this platform can not replicate the offline social network $100 \%$ because this SNS has lost its real relationship information between persons $\mathrm{A}$ and $\mathrm{B}, \mathrm{D}$ and $\mathrm{F}, \mathrm{G}$ and $\mathrm{F}, \mathrm{E}$ and $\mathrm{H}$.

From one SNS matrix table, if we can sum up each cell's value, we can get an "occupation or replication rate" of the real-world social network universe.

Sum of each cell value of Table $2=17$ or 9 (if counted symmetrically) Sum of each cell value of Table $3=8$ or 4 (if counted symmetrically) then the occupation rate is $47.1 \%\left(8^{*} 100 / 17\right)$ or $44.4 \%\left(4^{*} 100 / 9\right)$.

However, in reality, summarizing the real data of each cell's values of each SNS is difficult. Therefore, rather than summarizing each of the cell values of each of the SNSs within the matrix, we chose to use the average number of a friends list in each SNS, which comparatively easy to acquire.

In this way, we could formulate the value of an LPSN by using the variables of width rate and depth rate, where width rate means the number of service users among real population, and depth rate means the average number of friends per SNS compared to the Dunbar Number (an official average number of friends in real offline society) [2].

LPSN index $=$ width rate $\times$ depth rate

With this formula, we were able to produce LPSN values for each SNS, compare them to each other, as in Tables 4-7, and discover why the index value of the LPSN is so important in order to defeat the first entrant or to block newcomers. 
We compared each pair by considering when the first entrant had its peak value as an LPSN and when it was surpassed by a newcomer.

Table 4 shows that NateOn's LPSN far exceeded that of MSN.

Table 4. LPSN index comparison between MSN vs. NateOn.

\begin{tabular}{ccc}
\hline & MSN (2003) & NateOn (2008) \\
\hline $\begin{array}{c}\text { Nation usage rate } \\
(=\text { width rate) }\end{array}$ & $13 \%$ & $27 \%$ \\
$\begin{array}{c}\text { Average Num. of friends } / 150 \\
(=\text { depth rate) }\end{array}$ & $33 / 150=22 \%$ & $40 / 150=27 \%$ \\
LPSN index = width rate*depth rate & $2.86 \%$ & $7.29 \%$ \\
\hline
\end{tabular}

Table 5. LPSN index comparison between NateOn vs. KakaoTalk.

\begin{tabular}{ccc}
\hline & NateOn (2008) & KakaoTalk (2013) \\
\hline $\begin{array}{c}\text { Nation usage rate } \\
(=\text { width rate })\end{array}$ & $27 \%$ & $34 \%$ \\
$\begin{array}{c}\text { Average Num. of friends } / 150 \\
(=\text { depth rate })\end{array}$ & $40 / 150=27 \%$ & $65 / 150=43 \%$ \\
LPSN index = width rate*depth rate & $7.29 \%$ & $15 \%$ \\
\hline
\end{tabular}

In Table 5, we can see KakaoTalk's LPSN far exceeded that of NateOn.

In Table 6, we can see Facebook's LPSN far exceeded that of Myspace.

Table 6. LPSN index comparison between Myspace vs. Facebook.

\begin{tabular}{ccc}
\hline & Myspace (2011) & Facebook US. (2013) \\
\hline $\begin{array}{c}\text { Nation usage rate } \\
(=\text { width rate })\end{array}$ & $32 \%$ & $58 \%$ \\
$\begin{array}{c}\text { Average Num. of friends } / 150 \\
(=\text { depth rate) }\end{array}$ & $68 / 150=45 \%$ & $120 / 150 \%=80 \%$ \\
LPSN index = width rate*depth rate & $14 \%$ & $50 \%$ \\
\hline
\end{tabular}

In Table 7, we can see Facebook's LPSN exceeded that of Cyworld.

Table 7. LPSN index comparison between Cyworld vs. Facebook.

\begin{tabular}{ccc}
\hline & Cyworld (2011) & Facebook Korea (2013) \\
\hline $\begin{array}{c}\text { Nation usage rate } \\
(=\text { width rate) }\end{array}$ & $53 \%$ & $26 \%$ \\
$\begin{array}{c}\text { Average Num. of friends } / 150 \\
(=\text { depth rate) }\end{array}$ & $50 / 150=33 \%$ & $120 / 150 \%=80 \%$ \\
LPSN index = width rate*depth rate & $17 \%$ & $21 \%$ \\
\hline
\end{tabular}

We can see below in Table 8, the summary of national usage rate, the average number of friends per each SNS in the related year. 
Table 8. Comparison of the number of subscribers/unique visitor/average friends lists per social network cases within the research period.

\begin{tabular}{|c|c|c|c|c|c|c|c|c|}
\hline & 2003 & 2005 & 2007 & 2008 & 2009 & 2010 & 2013 & 2018 \\
\hline Population of Korea (1000) & 47,890 & 48,180 & & 49,050 & & 49,550 & 50,430 & 51,000 \\
\hline Internet users of Korea (1000) & $28,000(58 \%)$ & $33,000(72.8 \%)$ & & $35,000(76.5 \%)$ & & & $40,000(82.1 \%)$ & $46,000(90 \%)$ \\
\hline Cellphone users of Korea (1000) & 34,000 & & & 46,000 & & & 48,000 & 50,000 \\
\hline Smartphone users of Korea (1000) & 0 & & & 0 & & $(30 \%)$ & $37,500(74 \%)$ & $50,000(98 \%)$ \\
\hline Population of US (1000) & about 300,000 & & & about 300,000 & & 300,000 & about 300,000 & about 300,000 \\
\hline Internet users of US & $61 \%$ of adults & & & $74 \%$ & & & $84 \%$ & $89 \%$ \\
\hline Cellphone users of US & $63 \%$ of adults & & & $77 \%$ & & & $89 \%$ & $95 \%$ \\
\hline Smartphone users of US & 0 & & & 0 & & & $56 \%$ of adults & $77 \%$ \\
\hline MSN (Korea) (1000) & 6000 & 4000 & & 4000 & & & 0 & 0 \\
\hline Nation usage rate & $13 \%$ & $8 \%$ & & $8 \%$ & & & & \\
\hline Average \# of friends/150 (Dunbar\#) = depth rate & $33 / 150=22 \%$ & & & $39 / 150=26 \%$ & & & & \\
\hline LPSN index $=$ width $*$ depth & $2.86 \%$ & & & $2 \%$ & & & & \\
\hline NateOn (1000) & 0 & 10,000 & & 13,000 & & & 4500 & 1000 \\
\hline Nation usage rate & & $20 \%$ & & $27 \%$ & & & $9 \%$ & \\
\hline Average \# of friends/150 (Dunbar\#) = depth rate & & $12 / 150=8 \%$ & & $40 / 150=27 \%$ & & & & \\
\hline LPSN index $=$ width*depth & & $1.6 \%$ & & $7.29 \%$ & & & & \\
\hline KakaoTalk (PC/Mobile) (1000) & 0 & & & 0 & & & $17,000 / 25,000$ & $/ 50,000$ \\
\hline Nation usage rate & & & & & & & $34 \%$ & $97 \%$ \\
\hline Average \# of friends/150 (Dunbar\#) = depth rate & & & & & & & $65 / 150=43 \%$ & $100 / 150=67 \%$ \\
\hline LPSN index $=$ width $*$ depth & & & & & & & $15 \%$ & $65 \%$ \\
\hline Cyworld (1000) & 3500 & & & 20,000 & & 26,000 & $9000 \mathrm{UV} /$ month & 3000 \\
\hline Nation usage rate & & & & & & $52.4 \%$ & $18 \%$ & \\
\hline Average \# of friends/150 (Dunbar\#) = depth rate & & & & $40 / 150=27 \%$ & & $50 / 150=33 \%$ & $50(33 \%)$ & \\
\hline LPSN index $=$ width $*$ depth & & & & & & $26 \%$ & $6 \%$ & \\
\hline
\end{tabular}


Table 8. Cont.

\begin{tabular}{|c|c|c|c|c|c|c|c|c|}
\hline & 2003 & 2005 & 2007 & 2008 & 2009 & 2010 & 2013 & 2018 \\
\hline Myspace(US/Global) (1000) & 1000 & & & $115,000 / 200,000$ & & 95,000 & 20,000 & 10,000 \\
\hline US nation usage rate & & & & & & $32 \%$ & $7 \%$ & \\
\hline Average \# of friends/150 (Dunbar\#) = depth rate & & & & & & $68 / 150=45 \%$ & $68 / 150=45 \%$ & \\
\hline LPSN index $=$ width $*$ depth & & & & & & $14 \%$ & $3 \%$ & \\
\hline Facebook (PC/Mobile), Korea (1000) & 0 & & & $(100 / 0)$ & & & $13,000 \mathrm{UV} / \mathrm{month}$ & \\
\hline Nation usage rate & & & & & & & $26 \%$ & \\
\hline Average \# of friends/150 (Dunbar\#) = depth rate & & & & & & & $120 / 150=80 \%$ & \\
\hline LPSN index $=$ width ${ }^{*}$ depth & & & & & & & $21 \%$ & \\
\hline Facebook (PC/Mobile), US (1000) & 0 & & & $\begin{array}{c}(100,000 / 0) \text { global } \\
200,000\end{array}$ & & & $\begin{array}{c}\text { (global } \\
1,300,000 / 900,000)\end{array}$ & $\begin{array}{c}\text { (global 220,0000/global } \\
1,400,000)\end{array}$ \\
\hline US nation usage rate & & & & & & & $58 \%$ & $68 \%$ \\
\hline Average \# of friends/150 (Dunbar\#) = depth rate & & & & & & & $80 \%$ & \\
\hline LPSN index $=$ width $*$ depth & & & & & & & $50 \%$ & \\
\hline
\end{tabular}




\section{Discussion}

\subsection{Disproof of "Open API is the Most Important Factor Explaining Why Facebook Defeated All Competitors"}

In our arguments, we did not agree that the API alone is the main reason for network effect failure, especially in the SNS industry [19]. We learned, through our multiple case studies, that even before Facebook executed its API strategy, it had already conquered Myspace. Thus, although an API can be a necessary condition to make it stronger, by itself, it cannot cause the network effect to arise or be sustained. Moreover, Cyworld copied the API strategy after Facebook, but it did not work.

\subsection{Disproof of "New Technology or Mobile is the Most Important Factor to Explain Network Effect is Reversed"}

In 2007, Myspace was the largest SNS in the United States. However, in 2013, its position was reversed by latecomer Facebook. Unlike Korea, the United States still had an bigger LPSN in the PC space in 2013. Myspace did not have more than 30\% of the offline social network as its users and failed to keep building up the offline social network databases. In the end, even within the PC space, Myspace was defeated by Facebook. In addition, as the mobile space provided a larger social network container, Facebook steadily collected more offline social networks using its mobile app [5].

In 2013, in the US, most users accessed SNSs through their PC rather than their mobile device because the mobile penetration rate was not that high yet in the US. Facebook had already surpassed Myspace in the US in terms of monthly active users, especially by occupying offline social networks, which had been accumulated with most of the university students and high-schoolers in the US. Facebook had also a strong presence in foreign countries through university and college students abroad [5]. These facts show that, even before the mobile era arrived, Myspace was thoroughly defeated by Facebook. This was not because of mobile or technology change, but because of a lack of effort to incorporate real offline social networks into their existing service. Myspace killed and destroyed existing precious relationship links built among real friends. Before 2013, Myspace was the representative SNS in the United States. Myspace was acquired by Rupert Murdoch's News Corporation at about 700 million USD. At this time, Mark Zuckerberg of Facebook said that it was a matter of time before Myspace was overtaken by Facebook because the new owners did not understand the nature of the social network. Mike Jones, former president of Myspace, said in an interview, "I believe that Facebook was able to keep up with Myspace because it made the social network perfect, whereas Myspace just introduced the social network to people" [5]. Myspace encouraged anonymous systems, which increasingly hindered the enjoyment of social networks. On the other hand, Facebook continued to encourage people to use their real names. This important difference in the two SNSs will serve as a game-changer in the future. Using an individual's real name meets the basic requirements for bringing offline social networks online.

\section{Conclusions}

\subsection{Summary}

The four cases above are illustrated in this graph in Figure 13, which shows a shift of the LPSN from PC to mobile.

Even before the mobile era began, Facebook had outpaced Cyworld and Myspace. As the mobile age emerged, KakaoTalk easily defeated NateOn. The winners focused on their occupation of the LPSN, wherever it exists. That means that we can now answer the research question, "How can the largest SNS sometimes collapse?" through hypothesis-building. 


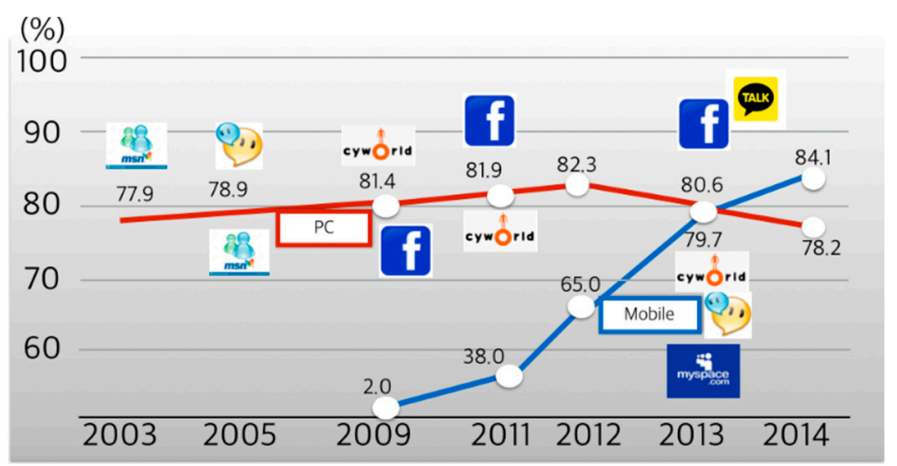

Figure 13. LPSN shift from PC to mobile in 2013 in Korea.

Hypothesis: "If any SNS cannot occupy a majority of the offline social network universe, it can fail at any time if another continues to occupy the LPSN faster than the first." Or "The SNS which can make the value of "width rate $\times$ depth rate (= LPSN index)" larger than its competitor wins the market, where width rate $=\#$ of active users/offline population, depth rate $=$ average \# of connected friends/150 (= Dunbar Number)".

Although Facebook enjoys exclusive worldwide network effects, more than $51 \%$ of the 7.5 billion people on offline social networks are not yet registered to Facebook. In addition, many Facebook users are leaving. According to our hypothesis, there may still be opportunities for a latecomer, particularly if it can get ahead by occupying (fetching not only nodes but also links) the remaining $51 \%$ of the offline social network market in response to the paradigm shifts from future hardware changes or innovative technologies. If new mediums or technologies emerge which can be far more closely or heavily used to suit each individual's daily behaviors, and they can reflect more realistic social networks, there is a theoretical plausibility that Facebook can collapse. In previous sections, we hypothesized that an SNS which occupies the majority of offline social network universe would be the last winner in exercising the everlasting network effect. As the technology innovation migrates from PCs to cellular phones, and from cell phones to smartphones, in turn, the use of an innovative media to better capture offline social networks is essential to maximize or sustain network effects. Still, merely migration to the mobile world or new tech platform is not enough. The focus should be kept on accumulating offline social networks (which consist of nodes and links). For example, a service which enables people to share their implicit experience data (tacit data) with others on a "trust-based" and "social process re-engineering" basis, such as that which was somehow executed by Activenet (acquired by Oracle) in the B2B market first [34], could defeat Facebook.

\subsection{Contribution}

According to the results of this research, the network effect is never dead [35]. The network effect, at least in terms of the SNS industry (including both Facebook and messenger services), in order to be maximized needs to occupy most of the offline social network. Paradoxically, the contribution of this study is that the first-mover company's failure, despite the existing network effect, did not occur because there was no longer a "network effect". However, it strengthened the importance of the network effect in the correct way, especially in the online/mobile SNS industry. Most of all, we answered the question, "Why and how are the largest SNSs sometimes unable to sustain themselves?" by supporting our hypothesis. According to Dul and Hak, hypothesis-building without hypothesis-testing has also valuable research significance [31].

There are two more contributing points. First, we can argue the API strategy for the sustainability of an existing SNS is not sufficient [19]. Facebook executed the API strategy only after they became successful at replicating offline social networks first (interweaving local networks to naturally produce global social networks on their platform.). Furthermore, even when Cyworld copied the API strategy of Facebook, they were unsuccessful because they did not continue to accumulate pure offline social 
networks into their existing platform first. Second, a timely accepting mobile or technology paradigm shift is not sufficient for sustaining existing network effects [20]. Facebook outwitted Cyworld and Myspace even before the mobile era had fully emerged. Cyworld or Myspace lost control because they did not continue to accumulate precious offline social network databases. This also means they did not raise the value of the LPSN index, depth rate (average number of friends on each SNS per Dunbar Number 150) or width rate (number of active users of SNS per local real population).

Considering the exact value of the LPSN index, we still cannot provide an exact standard value for an LPSN to outwit any competitor, whether the competitor is a newcomer or not. However, one certainty is that an LPSN index lower than $30 \%$ is dangerous and may cause an SNS to lose its control of the market, as can be seen in Table 8 .

Future research is needed. What factor will be the main force for network effect sustainability on other online platforms like Uber, Amazon, Netflix, and Airbnb?

\subsection{Implications}

First, our hypothesis can be utilized by practitioners in the SNS industry to decide if a new venture should be undertaken to defeat, for example, Facebook, WeChat, or if their existing SNS system is sufficient for maintaining their No. 1 position. Second, in academia, most articles are written with the assumption that all platforms are equal in terms of analyzing network effects. However, there are actually major differences among platforms. Amazon (a commerce platform), Airbnb, Uber (online to offline platforms), Facebook, LinkedIn (social network platforms), Pinterest and Twitter (content network platforms) have their inherent principles. For example, users of Amazon and Airbnb are not connected. Users of Pinterest do not have to know each other in Facebook or LinkedIn. This means the basic structure, content type, and user relation type of each service are different, which makes the network effect quite different. For example, you can use Amazon without your friends, but not Facebook. Nevertheless, Amazon and Facebook have their inherent network effects. In the SNS industry, the network effect occurs earlier, meaning that first entrants are not safe from latecomers. Myspace and Cyworld had a huge, rapid growth path with their network effects. However, because they did not replicate most of their offline social networks (which are a kind of "mother set" or large set) sufficiently, they eventually could not maintain their first-entrant advantage.

Author Contributions: Conceptualization, Y.J.H. and K.J.L.; Case Study Methodology, A.P.; Validation, Y.J.H. and K.J.L.; Formal Analysis, Y.J.H. and K.J.L.; Investigation, Y.J.H.; Resources, Y.J.H.; Writing-Original Draft Preparation, Y.J.H.; Writing-Review \& Editing, K.J.L.; Supervision, K.J.L. All authors have read and agreed to the published version of the manuscript.

Funding: This work was funded by the Ministry of Education of the Republic of Korea and the National Research Foundation of Korea (NRF-2017S1A5B8059804).

Acknowledgments: The authors give special thanks to Neena Bucks( A researcher in MIT)'s friendly review and editing help.

Conflicts of Interest: The authors declare no conflict of interest.

\section{References}

1. Yin, R.K. Case Study Research and Applications: Design and Methods, 2nd ed.; Sage Publishing: Thousand Oaks, CA, USA, 1994.

2. Dunbar, R. How Many Friends Does One Person Need? Dunbar's Number and Other Evolutionary Quirks; Faber and Faber: London, UK, 2010.

3. Heo, M. NateOn vs. MSN Messenger, NateOn Totally Won! Available online: http://www.inews24.com/ view/538410 (accessed on 29 March 2010).

4. Lee, C. KakaoTalk vs. NateOn, 'Collide' in PC Messenger Market. Available online: https://www.seoulfn. com/news/articleView.html?idxno=164806 (accessed on 29 May 2013).

5. Diffen. Facebook vs. Myspace. Available online: https://www.diffen.com/difference/Facebook_vs_MySpace (accessed on 9 May 2014). 
6. Ghedin, G. Social Media in South Korea: How Facebook Won Cyworld. Available online: http://www. digitalintheround.com/south-korea-cyworld-facebook/ (accessed on 4 April 2013).

7. Aggarwal, C.C.; Yu, P.S. On the network effect in Web 2.0 applications. Electron. Commer. Res. Appl. 2012, 11, 142-151. [CrossRef]

8. Coolican, D.; Jin, L. The Dynamics of Network Effects. Available online: https://a16z.com/2018/12/13/networkeffects-dynamics-in-practice/ (accessed on 1 May 2019).

9. Czajkowski, M.; Sobolewski, M. How much do switching costs and local network effects contribute to consumer Lock-In in mobile telephony? Telecommun. Policy 2016, 40, 855-869. [CrossRef]

10. Luarn, P.; Yang, J.C.; Chiu, Y.P. The network effect on information dissemination on social network sites. Comput. Hum. Behav. 2014, 37, 1-8. [CrossRef]

11. Fainmesser, I.P.; Galeotti, A. Pricing Network Effects. The review of economic studies limited. Rev. Econ. Stud. 2016, 83, 165-198. [CrossRef]

12. Engel, K.L. Instant Messengers: What Happened to ICQ, AIM \& MSN? Available online: https://www. whoishostingthis.com/blog/2014/10/22/instant-messengers/ (accessed on 7 April 2018).

13. Katz, M.; Shapiro, C. Network Externalities, Competition, and Compatibility. Am. Econ. Rev. 1985, 75, 424-440.

14. Katz, M.; Shapiro, C. Systems Competition and Network Effects. JEP 1994, 8, 93-115. [CrossRef]

15. Church, J.; Gandal, N.; Krause, D. Indirect Network Effects and Adoption Externalities. RNE $2008,7$. [CrossRef]

16. Corrocher, N.; Zirulia, L. Me and you and everyone we know: An empirical analysis of local network effects in mobile communications. Telecommun. Policy 2009, 33, 68-79. [CrossRef]

17. Choi, B.H. A Study on Online IM (Instant Messenger) Development in China (Focusing on Network Effect for QQ Messenger Users). Donga Res. 2011, 60, 117-155.

18. Ryu, D.H.; Kim, K.S.; Park, T.W. Business Strategy of Facebook Who Declared Social App Platform. Available online: http://www.itfind.or.kr/WZIN/jugidong/1506/file43237-150603.pdf (accessed on 29 July 2011).

19. Shevlin, R. APIs Are Killing the Network Effect. Available online: https://www.crnrstone.com/insightvault/ 2018/06/25/apis-killing-network-effect/ (accessed on 25 June 2018).

20. Jin, D.S. Factors affecting success and failure of Internet company business model using inductive learning based on ID3 algorithm. J. Korea Inst. Inf. Commun. Eng. 2019, 23, 111-116.

21. Lee, M.B. A Study on Exploring Factors Influencing Continuance Intention in the SNS. J. Korea Ind. Inf. Syst. Res. 2011, 16, 151-161. [CrossRef]

22. Choudary, S.P. Reverse Network Effects: Why Today's Social Networks Can Fail as They Grow Larger. Available online: https://www.wired.com/insights/2014/03/reverse-network-effects-todays-social-networkscan-fail-grow-larger/ (accessed on 1 March 2014).

23. Hagiu, A.; Rothman, S. Network Effects Aren't Enough. HBR, April 2016.

24. Quora. When Do Network Effects Break Down? Available online: https://www.forbes.com/sites/quora/2018/ 01/25/when-do-network-effects-break-down/\#277cee507e89 (accessed on 25 January 2018).

25. Tucker, C. Why Network Effects Matter Less Than They Used To. HBR, 22 June 2018.

26. Carminati, B.; Ferrari, E.; Girardi, J. Trust and Share: Trusted Information Sharing in Online Social Networks. In Proceedings of the 2012 IEEE 28th International Conference on Data Engineering, Arlington, VA, USA, 1-5 April 2012.

27. Huang, Z.; Janz, B.D. Internet EDI adoption Trust in technology and application knowledge. In Proceedings of the Eighth Americas Conference on Information Systems, Dallas, TX, USA, 9-11 August 2002.

28. Angela, A. Network Effects on Social Platforms: Why the Quality of User Matters. Available online: https://versionone.vc/quality-network-effects/ (accessed on 16 September 2015).

29. Schenke, M. Former Myspace CEO Explains Why Myspace Lost Out to Facebook so Badly. Available online: https://www.digitaltrends.com/social-media/former-myspace-ceo-reveals-what-facebook-did-rightto-dominate-social-media/ (accessed on 12 May 2015).

30. Sun, Y.; Han, J. Mining Heterogeneous Information Networks: Principles and Methodologies. Synth. Lect. Data Min. Knowl. Discov. 2012, 3, 1-159. [CrossRef]

31. Dul, J.; Hak, T. Case Study Methodology in Business Research; Routledge: Abingdon-on-Thames, UK, 2008.

32. Bent, F. Five Misunderstanding About Case-Study Research. Qual. Inq. 2006, 12, 219-245. 
33. Bandara, W.; Gable, G.G.; Rosemann, M. Factors and measures of business process modelling: Model building through a multiple case study. Eur. J. Inform. Syst. 2005, 14, 347-360. [CrossRef]

34. Kanaracus, C. Oracle Buys IP from Tacit to Boost Beehive Platform. Available online: https://www.infoworld. com/article/2642010/oracle-buys-ip-from-tacit-to-boost-beehive-platform.html (accessed on 3 November 2008).

35. Weiss, G.L.; Start-Up Nation Central. Network Effects Are Becoming Even More Important on Emerging Platforms. Available online: https://www.forbes.com/sites/startupnationcentral/2018/03/18/why-a-networkeffect-is-the-only-way-your-startup-can-win/\#73a3165b7527 (accessed on 18 March 2018).

C 2020 by the authors. Licensee MDPI, Basel, Switzerland. This article is an open access article distributed under the terms and conditions of the Creative Commons Attribution (CC BY) license (http://creativecommons.org/licenses/by/4.0/). 